\title{
¿QUÉ HACER \\ CON LOS UNIVERSALISMOS OCCIDENTALES?
}

\author{
Santiago Castro-Gómez'
}

RESUMEN: Este artigo analiza cierta visión de la "teoría decolonial" que rechaza cualquier pretensión de universalidad del pensamiento, asociando esta afirmación al eurocentrismo. Contrariamente a esta visión, presenta efectivamente la imposibilidad de particularizar las identidades, ya que estas resultan dentro de la combinación de las redes de relaciones que las posibilitan. La idea de una "identidad cultural" es siempre originada por la cristalización temporal de determinadas relaciones de poder. Así, una política emancipadora debe radicalizar lo universal, negando la universalidad "incompleta" y "abstracta" de los grupos hegemónicos. El eurocentrismo es una forma singular de relacionar lo universal y lo particular, que no puede ser aceptada como la única posible. El verdadero rechazo al universalismo europeo no puede confundirse con un rechazo de la universalidad emancipadora, más bien debe buscar una perspectiva común que vaya más allá del particularismo. Por lo tanto, los "sin parte" tiene que poner constantemente en tela de juicio la idea hegemónica de la universalidad que los excluye. Si hay una "necesidad" en lo universal, su construcción circunstancial se llevará a cabo en la lucha política. 
PALAVRAS-CLAVE: Universal; Eurocentrismo; Laclau; Teoría Decolonial; Žižek.

\begin{abstract}
This paper discusses a certain view of the "decolonial theory" that refuses any pretension of universality to thought, associating this pretension with a necessary Eurocentrism. In contrast to this view, it shows the effective impossibility of the particularism of identities, since they are always conjugated in a network of relationships that make them possible. The idea of a putative original "cultural identity" always represents the temporal crystallization of certain power relations. Thus, an emancipatory policy must radicalize universality, denying the "incomplete" and "abstract" universality of hegemonic groups. Eurocentrism is a particular form of relation between the universal and the particular, and cannot be accepted as the only possible. The correct refusal of European universalism cannot be confused with a refusal to emancipatory universality, which seeks a common perspective that goes beyond particularisms. To this end, those "without part" must constantly challenge the hegemonic idea of universal, which excludes them. If there is no "necessity" in the universal, its contingent construction will result from political struggle.
\end{abstract}

KEYWORDS: Universals; Eurocentrism; Laclau; Decolonial Theory; Žižek. 
Desde hace ya tiempo se ha venido asentando en ciertos círculos de izquierdas en América Latina la tesis de que el propósito central de una "teoría decolonial" es la denuncia del eurocentrismo. Se piensa además que la "descolonización" de las ciencias sociales, el arte y la filosofía radica en recuperar el conocimiento ancestral de las comunidades indígenas o afro-descendientes, pues allí se encontraría un ámbito de "exterioridad" capaz de interpelar los conocimientos y las prácticas provenientes de Europa a través de la colonización. Finalmente se dice que el propósito de una teoría crítica "desde América Latina" sería negar toda pretensión de universalidad, pues se sospecha que el universalismo es una ideología perteneciente a la historia local europea, y que exportarla hacia otros ámbitos culturales conllevaría reproducir un gesto colonial que debe ser desechado. En este trabajo quisiera presentar algunos argumentos que cuestionan estas posiciones. En primer lugar preguntaré si es posible pensar las identidades culturales en términos particularistas. Luego abordaré el problema del eurocentrismo, tratando de dilucidar a qué tipo de fenómeno específico puede ser aplicable este término. Enseguida me moveré hacia el tema del universalismo, mostrando que la política emancipatoria no puede renunciar al gesto de la universalización de intereses ${ }^{2}$. Finalmente quisiera articular algunas reflexiones en torno a la noción de "transmodernidad", desarrollada en América latina por el filósofo argentino Enrique Dussel.

\section{LA IMPOSIBILIDAD DEL PARTICULARISMO DE LAS IDENTIDADES}

La primera pregunta que quisiera levantar es si las identidades culturales pueden ser pensadas como 
particularidades puras, esto es, como fenómenos que se constituyen sólo en relación consigo mismos, con su propia tradición ancestral, y que existen con total independencia de sus relaciones con el exterior, a la manera de mónadas autosuficientes. De entrada diré que la respuesta a esta pregunta debe ser negativa. ¿Por qué razón? Porque no es posible comprender el sentido y la función de una práctica cualquiera si la abstraemos de la red de relaciones que la hace posible. No existe ninguna práctica que tenga sentido por sí misma, con independencia de la posición y la función que ocupa en una red de relaciones diferenciales. Esta, me parece, es una de las lecciones básicas que aprendemos tanto de la deconstrucción de Jacques Derrida como de la analítica del poder de Michel Foucault. Derrida, recordémoslo, parte de la lingüística de Saussure para mostrar que todo acto significativo sólo se define únicamente al interior de un sistema de diferencias. Cada signo se define no por unas propiedades esenciales, sino por las diferencias que lo distinguen de otros signos. Es decir que el signo no tiene identidad consigo mismo; la identidad plena del signo es algo que se le "escapa" constantemente, pues esta dependerá siempre de la posición diferencial de ese signo en el sistema de significaciones. Esto quiere decir que en cualquier cadena de significaciones todo elemento siempre remite a otro, es decir que cada elemento se constituye sólo a partir de la "huella" que dejan en él los demás elementos con los que se relaciona. Derrida nos dice que en un sistema de este tipo no puede pensarse algo así como una «armonía preestablecida» entre los elementos, es decir, un principio que regule la posición que ocupa cada uno de ellos en el sistema y establezca de antemano el tipo y el número de relaciones que 
entabla con todos los demás elementos. Si esto ocurriera, lo que tendríamos sería un sistema cerrado, libre de diferencias, pero entonces quedaría cerrada también la posibilidad de la significación.

Foucault, por su parte, nos dice que toda comunidad humana se encuentra atravesada por relaciones de fuerza, lo cual quiere decir que ninguna fuerza particular puede definirse con independencia del sistema de fuerzas que la constituye, bien sea como fuerza afectante o como fuerza afectada. Esto significa que ningún elemento de una comunidad puede existir sino referido a las relaciones de fuerza que entabla con todos los demás elementos. Este modelo agonístico del poder apunta hacia la tesis de que ninguna formación social jamás podrá llegar a encerrarse en sí misma. El agonismo de las fuerzas engendra siempre nuevas y variadas configuraciones de poderes y contrapoderes, de modo que resulta imposible que una comunidad cualquiera pueda "completarse" y adquirir una identidad esencial. Siempre será una comunidad incompleta, pero no porque ontológicamente le falte algo, sino porque la dinámica de las fuerzas genera siempre nuevos pliegues y nuevas combinatorias diferentes de sus elementos. En precisamente en este sentido que todas las comunidades humanas son históricas.

Todo esto quiere decir, según Foucault, que no es posible buscar un "origen" último (Ursprung) que le dispense sentido y finalidad al sistema de fuerzas en su conjunto. Al igual que Derrida, Foucault afirma que la existencia de un "origen" anularía el juego agonístico de las fuerzas. Pero es precisamente esta falta de origen lo que hace que el juego de las fuerzas tenga siempre un final abierto, esto es, que exista un relación no determinable de antemano entre los poderes y los contrapoderes. Si existiera 
un "origen" que definiera de antemano esas relaciones, entonces no tendríamos juego alguno. Lo que tendríamos sería un sistema muerto, cerrado en sí mismo, en el que ninguna incitación mutua de las fuerzas sería posible. Derrida diría, a su vez, que un sistema de significaciones no puede cerrarse nunca, porque para hacerlo, tendría que hacer referencia a una "archihuella" que se sustraería al juego de las diferencias y que imposibilitaría el acto mismo de significar. El vacío del origen es, entonces, la condición de posibilidad para que pueda existir la significación, lo cual quiere decir, a su vez, que todo sistema de relaciones significativas adolece de una «falta» que le es constitutiva y que impide que sus elementos se cierren por completo.

Ahorabien, sipensamoslas relaciones socialescomorelaciones significativas, en el estilo de Derrida, o bien como relaciones de fuerza, en el estilo de Foucault, el resultado es exactamente el mismo: las identidades sociales no tienen esencia, puesto que la fijación última del sentido es una imposibilidad estructural de la cadena de relaciones. Tan sólo serán posibles fijaciones parciales y precarias, ya que las identidades sociales no pueden ser pensadas con independencia del sistema de relaciones diferenciales del que forman parte. No existen, por tanto, identidades que no sean relacionales, tal como lo concluyó también el filósofo argentino Ernesto Laclau:

Aceptemos por un momento la posibilidad de que la armonía preestablecida fuera posible. En tal caso, los varios particularismos no estarían en una relación antagónica entre sí sino que coexistirían en una totalidad coherente. Esta hipótesis muestra claramente por qué el particularismo puro es, en última instancia, contradictorio. 
Porque si cada identidad está en una relación diferencial, no antagónica, con todas las demás identidades, la identidad en cuestión es puramente diferencial y relacional; en consecuencia, ella presupone no sólo la presencia de todas las otras identidades sino también el espacio global que constituye las diferencias como diferencias. Peor aún: como sabemos muy bien, las relaciones entre grupos se constituyen como relaciones de poder - es decir que cada grupo no es sólo diferente de los otros sino que en muchos casos constituye esa diferencia sobre la base de la exclusión y la subordinación de los otros grupos. Ahora bien, si la particularidad se afirma a sí misma como mera particularidad, en una relación puramente diferencial con otras particularidades, está sancionando el statu quo en la relación de poder entre los grupos. Esta es exactamente la noción de "desarrollos separados" tal como la formulara el apartheid: sólo se subraya el aspecto diferencial, en tanto que las relaciones de poder en el que este último se basa son sistemáticamente ignoradas ${ }^{3}$.

Lo que dice Laclau es que las identidades sociales no son esenciales, es decir que no se constituyen sólo en relación consigo mismas, con su propia tradición cultural, ni remiten tampoco a un origen (Ursprung), a un espacio ancestral «propio» que ofrecería, de una vez para siempre y sin relación con una exterioridad, los significados acerca de lo que un grupo «es». Tal posición, por desgracia bastante común en algunos círculos de izquierdas en América Latina, es políticamente conservadora, diría que incluso reaccionaria. Las luchas identitarias, sea cuales fueran (de género, raza, clase, orientación sexual, etc.), no pueden tener como objetivo político la afirmación de la propia identidad y al 
mismo tiempo verse a sí mismas como luchas progresistas, ya que con ello dejan intacto el sistema de relaciones que jerarquiza las identidades. Sancionan, como dice Laclau, el statu quo del sistema jerárquico inclusión/exclusión, reproduciendo de este modo la lógica del apartheid. Quien afirma una particularidad sólo puede hacerlo si reconoce, al mismo tiempo, el sistema relacional de fuerzas en el que esa particularidad se inscribe. Si la afirmación de la particularidad fuera el único principio aceptado de lucha, entonces la afirmación de cualquier particularidad debería ser igualmente válida, incluyendo, desde luego, la de aquellos grupos que han subordinado la identidad por la que se está luchando. Estamos, pues, frente a una paradoja insoluble.

Es claro entonces que la «identidad cultural» no es más que la cristalización temporal de ciertas relaciones de poder y no una esencia intemporal que pueda ser pensada con independencia de éstas. No hay manera de que una comunidad particular (sea indígena, negra, gay, musulmana, lésbica) viva una existencia independiente del sistema de relaciones de poder que la ha constituido precisamente como identidad subalterna. Es una ilusión creer que las comunidades subalternas viven como las mónadas de Leibniz, sin puertas y ventanas abiertas hacia el mundo exterior. Por eso Laclau dice que una lucha por la transformación de la condición subalterna de estas comunidades tiene que incluir la transformación del sistema de relaciones desigualitarias a partir del cual estas comunidades son definidas como subalternas. No es posible cambiar una relación de poder simplemente aferrándose a la diferencia cultural, es decir al particularismo de las identidades, dejando intocado el sistema de relaciones que trascienden esa particularidad. 
Quien lucha por cambiar su posición subalterna, tendrá que cambiar también las relaciones de poder que han definido esa posicionalidad particular, lo cual implica necesariamente aceptar que su identidad se verá también modificada. ${ }^{4}$ No se puede tener una cosa, sin tener también la otra. Modificar un sistema jerárquico de relaciones significa necesariamente modificar la particularidad de cada uno los elementos que se relacionan en ese sistema.

Tomemos el caso hipotético de una comunidad subalterna que se coloca a sí misma en una posición de completa exterioridad con respecto a la «cultura occidental», reclamando conocer la «verdad» de esa cultura (en tanto que esencialmente diferente a los valores que unifican a esa comunidad subalterna). Aquí lo que tendríamos es la negación de la lucha política en nombre de un esencialismo cultural. ¿Por qué razón? Ya lo hemos visto: sólo hay política si primero se reconoce que entre los adversarios existe una relación de antagonismo. Pero cuando una de las partes niega (por la razón que fuese) la existencia de tal relación, poniéndose a sí misma en un lugar de exterioridad radical frente al sistema de relaciones antagónicas que ha constituido a unos como colonizadores y a otros como colonizados, a unos como superiores y a otros como inferiores, entonces la política ya no sería posible. La fórmula es simple: allí donde hay esencialismos no puede haber política, y allí donde hay política no puede haber esencialismos. La exterioridad, como veremos más adelante, únicamente puede entenderse como exterioridad relativa.

De todo esto podemos concluir que una posición teórica "decolonial" no es aquella que busca la recuperación de la 
identidad cultural de los pueblos colonizados. Tal recuperación no es más que una quimera, pues ha sido, precisamente, el sistema-mundo moderno/colonial el espacio en que se han constituido las identidades de cada uno de los elementos que entraron en esa matriz de relaciones jerárquicas. Aquello que Mignolo llama la "diferencia colonial" sólo tiene sentido al interior de un sistema desigualitario de relaciones de poder y no debe ser pensada, por tanto, como una inconmensurabilidad de tipo cultural entre europeos y no europeos. Esto último nos conduciría directo a una especie de fundamentalismo culturalista de tipo conservador. Si tomamos, en cambio, la conquista de América como el momento de "emergencia" (Entstehung) de ese sistema diferencial de fuerzas, diríamos entonces que no hay una identidad indígena, negra o europea que sea previa a la consolidación de esa red geopolítica de relaciones. Lo que quiero decir es que las identidades son lo que son, únicamente a través de sus diferencias en una matriz de relaciones jerárquicas de poder que organiza la posición ocupada por cada una de ellas. Pretender la "conservación" de la identidad cultural de los pueblos colonizados, o bien su "retorno" a una matriz identitaria ancestral, poco tiene que ver con una política emancipatoria. Esto equivaldría a sostener el absurdo de afirmar que existen pueblos colonizados sin colonialismo, es decir sin relaciones moderno/coloniales de poder. Pero decir esto, sostener que existen pueblos colonizados que no han sido afectados por las jerarquías de poder moderno/coloniales, que han vivido a espaldas de las relaciones que les han constituido precisamente como pueblos colonizados, ¿no significa negar el gesto mismo de la política? Este tipo de representación, que afirma la diferencia pero 
sacándola de la red de antagonismos que la hace posible para contemplarla como un objeto impoluto y distante, no es otra cosa que una representación colonial.

\section{2. ¿QUÉ ES EL “EUROCENTRISMO"?}

Es precisamente en nombre de este particularismo estéril que muchos activistas y académicos de América Latina recurren frecuentemente a la sospecha de «eurocentrismo» y «colonialismo intelectual» como eje catalizador de sus luchas. No son pocos quienes afirman que «pensar desde América Latina» significa pensar por fuera de los parámetros de universalidad establecidos por la política moderna, ya que éstos son específicamente europeos y se montan sobre la exclusión sistemática de las culturas no europeas. En algunos circuitos teóricos de la región se viene imponiendo una especie de Abyayalismo que sustituye al Latinoamericanismo de las décadas anteriores, en el que se proclama un «desprendimiento» de la modernidad, incluyendo aquí las tradiciones críticas de la izquierda, para recuperar las «epistemes-otras» de los pueblos indígenas y afro-descendientes. Consideran, por tanto, "eurocéntrica" aquella posición que niega, en nombre de valores modernos (como la igualdad), la posibilidad de regresar a un arché, a una comunidad originaria en la que imperan valores radicalmente diferentes a los modernos.

¿Qué tan válidos pueden ser estos argumentos? Para dilucidar esto, quisiera considerar en primer lugar la posición del filósofo Slavoj Žižek. El argumento del 
esloveno es claramente hegeliano. Es cierto que los poderes coloniales europeos irrumpieron con violencia en el mundo de las sociedades no europeas, alterando sus costumbres y destruyendo el tejido cultural de su experiencia. Pero esto significa, precisamente, que la resistencia política frente a esta irrupción colonial debe echar mano del lenguaje del colonizador para llevar a cabo su lucha, en lugar de propugnar por un retorno a los lenguajes previos a la ocupación colonial. ¿Por qué razón? Porque sólo radicalizando la universalidad, es decir, universalizando su "punto de exclusión», podrá el movimiento descolonizador lograr sus objetivos. No lo conseguirá negando la universalidad y buscando un «retorno a los orígenes», un regreso a la situación pre-colonial, invocando el «rescate» de una identidad cultural olvidada. Esto equivaldría simplemente a reforzar la ideología en su expresión más reaccionaria: creer que es posible rasgar el velo de la negatividad y descubrir, más allá de ella, el secreto oculto de la reconciliación. A contrapelo de esto, el esloveno muestra que la lucha por la descolonización debe asumir plenamente la herencia europea, esto es, el gesto de la universalización, para desde ahí plantear sus demandas.

Žižek ilustra su punto con varios ejemplos. El más claro de ellos es el de los procesos de independencia poscolonial en el siglo XX, principalmente el de la India. Ante la crítica de muchos teóricos culturales indios de que el inglés les ha sido impuesto como lengua colonial y que la descolonización debería suponer un retorno a las lenguas nativas, el filósofo esloveno retoma el caso de los Dalits, aquellos sujetos tenidos como parias por el sistema tradicional de castas de la India. Precisamente fueron ellos, los que «no tenían 
parte» en ninguna de las castas, quienes reivindicaron el inglés como lengua nacional. Para los Dalits, el sistema colonial inglés creó las condiciones formales para que fueran vistos como sujetos jurídicamente iguales ante la ley. Antes de eso, en la situación pre-colonial, no gozaban de ningún derecho, sino que eran tenidos como un homo sacer. Lo que nuestro filósofo quiere decir es que la descolonización debe radicalizar la universalidad abstracta del legado colonial. No se trata, pues, en nombre de la descolonización, de liberarse de la universalidad (por considerarla un instrumento del colonizador), sino de apropiarse de ella para mostrar que esta universalidad es «incompleta», que ha dejado algo por fuera. La lucha no es entonces por desembarazarse de la universalidad, sino por encarnarla. Pues sólo cuando los que «no tienen parte» muestran que ellos son el punto que «niega» la universalidad abstracta, es cuando esa universalidad se torna realmente libertaria. En palabras de Žižek, «sólo cuando los indios abrazan el ideal democrático-igualitario, ellos llegan a ser más europeos que los europeos mismos».

Otro ejemplo es el de Malcom X, el activista afroamericano de los años sesenta. ¿Por qué coloca esta $\mathrm{X}$ en su nombre de pila? Con ello quería indicar que había perdido definitivamente la identidad que le ligaba con sus ancestros esclavos y que no era posible un retorno a sus "raíces étnicas». Pero es precisamente esta ausencia de identidad la que le abre la posibilidad de reinventarse a sí mismo, luchando por una identidad más universal incluso que la reclamada por los blancos. La lucha política de los sujetos que, como él, no «tienen parte» en la sociedad, no consiste en «volver» a la particularidad del grupo étnico, a una comunidad orgánica 
situada mitológicamente «antes de la caída». Consiste, más bien, en apropiarse de la universalidad abstracta que los blancos han reservado para ellos y hacerla concreta mediante su "punto de exclusión», aquel elemento que esa universalidad dejó por fuera. La universalidad sólo se hace efectiva cuando es apropiada por aquellos que fueron excluidos de la misma. La lucha de Malcom X no buscaba volver «más atrás» de la universalidad moderna, negándola en nombre de un retorno a los orígenes africanos de la identidad, sino llevarla «más allá» de los límites señalados por los esclavistas blancos. Se trata, entonces, de radicalizar la universalidad y no de abandonarla, como plantean hoy día muchos teóricos poscoloniales. Ya el propio Nelson Mandela se daba cuenta de que la supremacía blanca y la tentación del retorno a las raíces tribales, eran las dos caras de una misma moneda.

Aunque no comparto con Žižek varios elementos de su crítica, lo que quieren mostrar estos ejemplos es que la mejor forma de combatir el colonialismo y el eurocentrismo no es recluyéndose en la particularidad étnica y negando la universalidad por considerarla un instrumento en manos del colonizador. Al contrario, la lucha por la descolonización debe hacerse a través de la universalidad. Pero no se trata de una universalidad abstracta que niega la particularidad (universalismo), sino de una universalidad concreta que se construye a través de la particularidad. Hacer lo contrario, negar toda universalidad con el objetivo de liberar las particularidades oprimidas por el colonialismo, no es sólo un gravísimo error político, sino que es un mecanismo de despolitización que el esloveno denomina «arquepolítica». Es el intento de regresar a un arché, a una comunidad originaria, 
homogénea, encerrada en sí misma e inmune frente a todo antagonismo. Una comunidad en la que no hay «síntoma», donde no existe un punto de exclusión a partir del cual levantar una pretensión de universalidad. En su libro El espinoso sujeto, el filósofo presenta este problema como una clara línea divisoria entre la izquierda y la derecha: mientras que la derecha niega el universalismo y se contenta con la afirmación del particularismo puro, la izquierda en cambio sabe que no hay política emancipatoria sin universalismo y se opone a todo intento de mitologizar la particularidad.

¿Cómo pensar entonces este problema de la particularidad y la universalidad? O, para utilizar el lenguaje de Žižek, ¿cómo entender la relación entre la universalidad abstracta y la universalidad concreta? Como ya vimos, algunos activistas dicen que el universalismo es tan sólo una estrategia para legitimar la superioridad cultural de Europa sobre el resto del mundo, sancionando de iure los privilegios obtenidos de facto a partir del saqueo que produjo la colonización. Es por esto que, en su opinión, la lucha contra la descolonización implica necesariamente el abandono de la universalidad, ya que ésta es tan sólo un invento perteneciente a la historia local y particular europea. Desde este punto de vista, la universalidad tiene solamente un carácter ideológico. Cualquier lucha política que apele a criterios universales pecaría de "eurocentrismo", porque elevaría a un carácter general lo que tan sólo vale para una cultura en particular. ¿Qué diremos frente a esto? Es verdad que a través de la expansión colonial, Europa se empieza a ver a sí misma como la encarnación de funciones universales. Funciones que vienen definidas primero por el cristianismo (expansión colonial portuguesa y española) y 
más tarde por el racionalismo (expansión colonial inglesa y francesa). La cultura europea como encarnación de una forma humana universal que debía ser "comunicada» a todas las demás culturas, aún en contra de su propia voluntad. Las resistencias de las otras culturas eran vistas como prueba de su inferioridad, de su barbarismo, e incluso de su incapacidad constitutiva para acceder a lo universal. Aquí sin duda tienen razón las críticas que se han hecho al universalismo europeo desde posiciones feministas, decoloniales y poscoloniales. Pero, ¿conlleva todo esto la negación de la universalidad? Creemos que no, porque el problema que está en juego no es elegir entre lo universal y lo particular, sino comprender el tipo de relación que se da entre estos dos polos. No se trata de equiparar el eurocentrismo con la universalidad para después abandonar las dos cosas en nombre de la particularidad, sino de entender que eso que hoy llamamos "eurocentrismo» no es más que una forma específica de plantear la relación entre universalidad y particularismo que procede de la ilustración (Aufklärung).

Para comprender este problema debemos acudir de nuevo al filósofo argentino Ernesto Laclau, quien en su libro Emancipación y diferencia reconstruye en tres momentos la compleja relación histórica entre lo universal y lo particular. El primer momento corresponde a la filosofía antigua clásica (Platón), en la que las relaciones entre ambos elementos es de mutua exclusión. Lo universal está dado de antemano y puede ser aprehendido por la razón, pero ello conlleva necesariamente el abandono de toda particularidad, ya que ésta no es sino la corrupción de la universalidad. ${ }^{5}$ La relación entre los dos polos es esencialmente dicotómica: lo racional se opone a lo 
irracional y la verdad se opone a la apariencia, con lo cual se abren dos operaciones posibles: o bien lo particular se elimina a sí mismo para transformarse en el medio a través del cual la universalidad se manifiesta (que es la operación propiamente filosófica), o bien lo particular niega categóricamente lo universal afirmando su propio particularismo (que es la operación propiamente sofística). Dicho de otro modo, o eres un filósofo y puedes atrapar lo universal a través de la razón, o eres un sofista y te quedas atrapado en el mundo cavernícola de las particularidades. No existe mediación alguna entre estas dos posiciones. Tal mediación aparecerá sólo después con el cristianismo. Aquí lo universal no es accesible a través de una razón que se ha distanciado de lo particular, sino que se «encarna» en lo particular mismo. Es lo que ocurre en la Biblia cuando Dios revela su voluntad universal a los hombres mediante una serie de eventos esenciales que son opacos a la razón humana. ${ }^{6}$ Entre lo universal y lo particular no existe entonces una relación de exclusión mutua, como ocurría en la filosofía antigua, ya que Dios aparece como mediador entre los dos polos. De este modo aparece la idea de que existen agentes privilegiados de la historia (los profetas, el pueblo elegido) que son el vehículo de lo universal. Sin embargo, entre lo universal y la particularidad que lo encarna no existe todavía una conexión de orden racional. Su relación depende exclusivamente de la voluntad de Dios y no del uso humano de la razón.

Será apenas con el advenimiento del racionalismo que la conexión entre la universalidad y la particularidad que lo encarna se reviste de un carácter racional. Laclau muestra que el racionalismo moderno se deshace de la lógica cristiana de la 
encarnación, pues el papel de mediador entre lo universal y lo particular ya no lo asume Dios, sino la Razón. Si todo lo que existe debe ser transparente a la razón (pretensión central de la Aufklärung), se hace necesario eliminar la opacidad entre la universalidad y la particularidad que la encarna, con lo que aparece la idea de un cuerpo que es, en sí y por sí mismo, universal. Aquí es donde se ancla no sólo el eurocentrismo (Europa como cuerpo universal), sino también la idea marxista de que el proletariado es una clase universal:

Lo universal había encontrado su propio cuerpo, pero éste era aún el cuerpo de una cierta particularidad. De tal modo, la europea era una cultura particular y, al mismo tiempo, la expresión - ya no la encarnación - de una esencia humana universal [...] Aquí el problema es que no había medios intelectuales para distinguir entre el particularismo europeo y las funciones universales que se suponía que él encarnaba, dado que el universalismo europeo había precisamente construido su identidad a través de la anulación de la lógica de la encarnación y, como consecuencia, de la universalización de su propio particularismo. De tal modo, la expansión imperialista europea tenía que ser presentada en términos de una función universal de civilización, modernización, etc. ${ }^{7}$.

La vieja noción cristiana del «agente privilegiado de la historia» se une con la concepción iluminista de la relación entre lo particular y lo universal, para dar origen a eso que llamamos eurocentrismo. Europa se presenta como agente universal, bajo la convicción de que su cultura expresa principios incondicionales que derivan de privilegios 
epistemológicos y ontológicos. Lo universal no es resultado de la acción contingente de fuerzas antagónicas, sino la expresión trascendental de privilegios encarnados en actores específicos. Con lo cual queda claro que el problema del eurocentrismo no es la universalidad como tal, sino su concepción universalista del juego entre lo universal y lo particular. El eurocentrismo va de la mano con la tesis ilustrada de que existe un agente privilegiado de la historia cuyo cuerpo es expresión racional de una universalidad que lo trasciende. Entre el contenido universal y su expresión particular existe una relación de transparencia garantizada por la razón.

El eurocentrismo es, entonces, una forma peculiar de entender la relación entre lo universal y lo particular. Aquí, lo universal no se da a través de la particularidad, sino que existe con anterioridad a ella. Desde este punto de vista, el eurocentrismo es un término que refiere a una concepción clásica del universalismo y nada tiene que ver, por ejemplo, con reconocer que muchos de los adelantos técnicos, científicos y políticos que hoy día son patrimonio de la humanidad provienen de Europa. No hay entonces que confundir una posición anti-eurocéntrica con la negación de toda universalidad, pues ello nos conduciría a un callejón sin salida. Debemos entender que la mejor forma de combatir el colonialismo y el eurocentrismo no es recluyéndose en las particularidades culturales y negando la universalidad por considerarla un instrumento en manos del colonizador. Al contrario, la lucha por la descolonización debe hacerse afirmando la universalidad. Pero no se trata, como veremos, de una universalidad abstracta que niega la particularidad (es 
decir del universalismo), sino de una universalidad concreta que se construye a través de la particularidad. Hacer lo contrario, negar toda universalidad con el objetivo de liberar las particularidades oprimidas por el colonialismo, no es sólo un gravísimo error político, sino que es un mecanismo de despolitización.

Filosóficamente hablando, ¿qué es entonces el eurocentrismo? Es una forma equivocada de entender la relación entre lo universal y lo particular. Lo universal es visto aquí como un conjunto de valores que preexisten a las relaciones entabladas por los actores sociales, y que son encarnados por uno de ellos en particular, en este caso en los europeos. Como puede verse, el eurocentrismo es la otra cara del particularismo extremo que estudiábamos en la sección anterior. Ambas posiciones imaginan una situación en la que un elemento en particular se sustrae al sistema de relaciones que lo hace posible y encarna una verdad definida tan sólo a partir de sí misma. En el primer caso se trata de imaginar una identidad cultural indígena o afro-descendiente no contaminada por el sistema moderno/colonial de relaciones; en el segundo, una cultura europea que encarna valores universalmente válidos para todo el planeta. Con Laclau diremos entonces que el eurocentrismo es un término que refiere a una concepción clásica del universalismo y nada tiene que ver con el reconocimiento de que la universalidad es un factor clave para entender la política. No hay que confundir entonces el universalismo con la universalidad, ni confundir tampoco una posición anti-eurocéntrica con el puro y simple chauvinismo de las particularidades. 


\section{LA UNIVERSALIDAD COMO REQUISITO DE UNA POLÍTICA EMANCIPATORIA}

Como acabamos de ver, se ha hecho un lugar común en muchos grupos de izquierdas la sospecha de que detrás de toda pretensión de universalidad se esconde un interés particular, y que la crítica al eurocentrismo radica precisamente en el abandono de todo universalismo por considerarlo un instrumento colonizador. La universalidad es vista como un fenómeno propio y singular de la historia local europea, que fue exportado violentamente hacia otros contextos culturales gracias a la colonización, operando de este modo como una institución imperialista. En esta última sección quisiera discutir la pertinencia de tales argumentos.

Ante todo hay que decir que cuando se habla de universalidad, quienes se ocupan de la filosofía política usualmente piensan en propuestas teóricas como las de Rawls y Habermas. Ambos filósofos entienden que no puede haber política sin apelar a un "punto de vista moral» en el que un acuerdo sólo podrá ser aceptado como legítimo, si cumple una serie de requisitos procedimentales. Un acuerdo será universalmente válido cuando el procedimiento que lo hizo posible garantice que el resultado del mismo pueda ser aceptado por todos los participantes en la deliberación, con independencia de si ese resultado corresponde o no a sus intereses personales. Habermas en particular distingue entre el «discurso moral» y el «discurso ético». El discurso ético hace referencia a la deliberación en torno a lo que debe hacerse para llevar una «vida buena», para lo cual se tendrán en cuenta las normas ancladas en la cultura particular de 
los hablantes, que en todo caso permanecen anclados en un contexto específico. El discurso moral, por el contrario, no apela a los valores culturales de los hablantes sino que apela a juicios universales, pues su objetivo es la resolución imparcial y equitativa de los conflictos. Es decir que apelará a unos procedimientos de discusión que puedan ser aceptados como válidos por todos los participantes. Como puede verse, mientras que el discurso ético se ejerce siempre en un contexto específico, en el ethos de una comunidad histórica en particular, el discurso moral aspira a un reconocimiento universal de sus prescripciones, con total independencia de los ethoi particulares. La universalidad de la que aquí se habla no corresponde entonces a contenidos específicos, sino a los procedimientos que han de tenerse en cuenta para establecer esos contenidos.

No es extraño que este tipo de universalismo hay generado críticas provenientes sobre todo del feminismo y de la teoría poscolonial. Se sospecha que bajo esta razón universal se esconden siempre los intereses particulares de un sujeto varón, heterosexual, blanco, europeo, burgués, imperialista, de clase media, etc. El sociólogo puertorriqueño Ramón Grosfoguel nos dice, por ejemplo, que en tales universalismos «el sujeto epistémico no tiene sexualidad, género, etnicidad, raza, clase, espiritualidad, lengua ni localización epistémica en ninguna relación de poder, y produce la verdad desde un monólogo interior consigo mismo, sin relación con nadie fuera de sí». El universalismo sería tan sólo una particularidad más, un ethos que se postula como universal gracias a los privilegios que obtiene este sujeto epistémico de la dominación (colonial, machista, burguesa, capitalista) ejercida sobre otros. 
Grosfoguel sospecha con razón que los «universalismos occidentales» no son sino la otra cara de un eurocentrismo que legitima la superioridad de Europa sobre los pueblos sometidos a su dominio colonial. El universalismo corresponde a una encarnación cultural concreta (Europa), a un conjunto de valores dados a priori que preexisten a la política y que son usados como arma para someter a otras culturas y formas de vida tenidas como «barbaras». En esto concordamos plenamente con Grosfoguel, pero el problema es la conclusión que muchos activistas y académicos sacan de esta crítica: se argumenta que toda pretensión de universalidad debe ser abandonada por completo, a fin de procurar la liberación de las particularidades sometidas. De un rechazo (correcto) al universalismo, se pasa sin más a un rechazo (incorrecto) a la universalidad como gesto fundamental de la política emancipatoria. El resultado de esto, como veremos enseguida, es la incapacidad de articular una voluntad común que vaya más allá de los particularismos. La universalidad no preexiste a las prácticas articulatorias que la hacen posible (en esto se distingue del universalismo), sino que es un efecto de las mismas. Por ello, estoy de acuerdo plenamente con Žižek cuando afirma que la universalización de intereses es el gesto político por excelencia.

Pero, ¿cómo se produce esta universalización de intereses? Tal vez sea Rancière quien con mayor claridad vislumbra este problema. De él precisamente toma Žižek la idea de que los «sin parte» (el elemento sintomático de la sociedad) pueden asumir la voz de todos y cuestionar de forma radical el orden existente. ¿Qué significa esto? Que en toda sociedad hay «sujetos flotantes» que no encajan en el ordenamiento que 
esa sociedad considera útil, normal, funcional o deseable. Son entonces los "parias» de esa sociedad, aquellos cuya voz «no cuenta» en el reparto de lo sensible. El momento propiamente político es aquel en el que esos sujetos flotantes entablan un litigio frente al ordenamiento que los excluye. Pero atención: lo que cuestionan no es la exclusión que ellos en particular experimentan, sino el ordenamiento mismo en el cual esa exclusión tiene lugar. No piden ser incluidos en el mismo orden que les excluye («queremos tener una parte en ese orden»), sino cambiar las reglas que son válidas para todos («queremos otro orden»). De modo que, según el filósofo francés, la función política de los «sin parte» es «poner constantemente en juego lo universal bajo una forma polémica». Cuando esos sujetos flotantes «toman la palabra» (algo que supuestamente no «pueden» hacer, ya que se les considera inferiores), en realidad no están hablando por ellos mismos sino por todos. Lo que cuestionan no es tal o cual regla en particular que debe ser cambiada, sino la totalidad de las reglas de juego que organizan desigualitariamente la sociedad. Su voz, en este sentido, es universal. No están litigando por la desigualdad en particular que vale para ellos, sino por la desigualdad que vale para todos.

Rancière menciona como ejemplo el caso de «la muchacha negra que un día de diciembre de 1955, en Montgomery (Alabama), decidió permanecer en su lugar en el autobús». Cuando Rosa Parks hace lo que supuestamente no debía hacer (un negro no puede sentarse en el lugar del autobús que corresponde sólo a los blancos), no estaba exigiendo un derecho para ella, o para la comunidad negra en particular, y ni siquiera para los habitantes de Estados Unidos, sino para 
todos los que en cualquier parte del mundo son tratados desigualmente en las distintas jerarquías que componen el «orden social»: jerarquías de clase, género, edad, orientación sexual, trabajo, educación, política, etc. Pues en cada una de estas jerarquías siempre juega una distinción entre aquellos que tienen parte y aquellos que no la tienen. De tal modo que cualquiera de los «sin parte» en cualquiera de esas jerarquías de poder, podría levantarse y decir: "yo soy Rosa Parks». Nótese además que la universalidad que invoca ella no es abstracta (basada en los Derechos Humanos que dicen «todos los hombres son iguales»), sino que es concreta, pues -como diría Žižek- universaliza una particularidad. Al sentarse en el lugar «equivocado» del autobús, Rosa Parks está diciendo: «aunque soy mujer y soy negra, me considero igual a todos los que se sientan aquí». Eleva de este modo una pretensión de igualdad que no habla en nombre de una particularidad (las mujeres negras), sino de un nosotros universal.

Nótese entonces que la presuposición de igualdad es justo el principio democrático que invocan los «sin parte» para articular una política emancipatoria. Sus reclamos no hacen énfasis en el hecho de la diferencia (soy mujer, negra, pobre, lesbiana, etc.), sino en la condición de desigualdad. Al hacer lo que se supone que no puede hacer (alguien que ocupa un lugar inferior en una jerarquía de poder no puede «igualarse» con los que ocupan lugares superiores), Rosa Parks se apropia precisamente de aquello que se le niega y eleva una pretensión de universalidad que vale no sólo para ella, sino para todos los que son inferiorizados en cualquier jerarquía de poder. Lo cual significa que el combate a tales jerarquías no podrá hacerse en nombre de la diferencia y la particularidad, sino 
en nombre de la igualdad que invocan de manera abstracta los propios dominadores en sus constituciones democráticas. Como bien lo vio Žižek, la política emancipatoria radica en convertir esa universalidad abstracta en una universalidad concreta.

La negación de la universalidad no es entonces el camino para una política decolonial, tal como argumentan hoy muchos activistas. No es posible hacer política sin el gesto emancipatorio de la universalización de intereses, pues de otro modo, el gesto político se reduciría a la exaltación de los particularismos. Y este gesto, como ya vimos, no es solo filosóficamente cuestionable, sino que es políticamente conservador. La crítica a la universalidad abstracta del eurocentrismo no supone la negación de la universalidad, sino el paso de la universalidad abstracta a la universalidad concreta, tal como lo ha mostrado Žižek. El eurocentrismo defiende ciertamente una universalidad abstracta despojada ilusoriamente de todo contenido, que se postula sin embargo como fundamento de todos los contenidos. La universalidad concreta, por el contrario, se produce a través de su síntoma, es decir por medio de aquellos contenidos particulares que han sido negados por la universalidad abstracta. Esos contenidos particulares, en lugar de afirmarse en su propia particularidad, deben ser negados para que puedan insertarse en la forma universal, que de este modo se verá parcialmente «completada». No se niega la universalidad como tal, sino tan sólo la negación que la universalidad abstracta había establecido frente a determinados contenidos particulares.

Finalicemos entonces diciendo que si lo que busca una lucha decolonial es afirmar las particularidades culturales, 
entonces ha renunciado de entrada a la política y caído en brazos de un multiculturalismo que ofrece a cada particularidad lo que esta necesita para reconocer su "identidad". Una política emancipatoria no es aquella que lucha por el reconocimiento de las formas de vida particulares, sino una que recurre a la universalización de intereses para combatir el "marco" que organiza desigualitariamente la sociedad. Pues, en últimas, es el mercado capitalista el que hoy día permite que cada particularidad pueda gozar de su estilo de vida. Hay productos de todo tipo para la comunidad gay y para las lesbianas, hay tiendas especializadas en música étnica, hay ropa y emblemas para los punks, mercados de artesanías indígenas, restaurantes de comida vegetariana, especies provenientes de la India, Tailandia, etc. Así las cosas, una política emancipatoria no es aquella que renuncia a la universalidad con el argumento de que toda universalidad es eurocéntrica y colonialista. Es, por el contrario, una que rechaza el universalismo eurocéntrico en nombre de la universalidad, pues sabe que su objetivo último es la lucha contra la desigualdad, donde quiera que esta se manifieste. Afirmar en cambio el particularismo de las identidades equivale a renunciar a la universalización de lo particular, es decir al gesto político por excelencia, tal como lo muestran tanto Žižek como Rancière y Laclau. Equivale a dejar la puerta abierta al multiculturalismo de las identidades, en donde las luchas políticas se mueven cómodamente al interior del marco desigualitario que organiza la sociedad, pero sin cuestionarlo jamás.

Desde este punto de vista, lo universal no tiene contenidos necesarios, sino que todos ellos son "puestos» de manera contingente a través de operaciones políticas. Lo cual quiere 
decir que lo universal no es una forma común a todos los humanos encarnada en un actor particular (Europa), sino una aspiración que debe ser «llenada» parcialmente a través de las luchas políticas. Es decir que no es un procedimiento que precede a la discusión política y la regula (como en Rawls y Habermas), sino un efecto contingente de operaciones equivalenciales (como en Laclau). Así las cosas, resulta claro que un llamado al particularismo extremo, tal como se da por ejemplo en las políticas de la diferencia en Europa y los Estados Unidos, pero también en ciertas concepciones "abyayalistas» ${ }^{8}$ en América Latina, no aporta mucho a las luchas progresistas. Insistimos: no es posible ningún tipo de política emancipatoria sin la universalización de intereses. Negar la universalidad no es entonces el camino adecuado para superar el eurocentrismo.

\section{TRANSMODERNIDAD}

Como hemos venido argumentando, una política emancipatoria no es aquella que se repliega en la reconstitución de los tejidos comunitarios, poniéndose de espaldas a la transformación de las relaciones de poder que han subalternizado a esas comunidades. Esto no significa en absoluto que los valores anclados y vividos en esas comunidades no puedan ser importantes a la hora de pensar un proyecto emancipatorio de izquierdas en América Latina. Y es aquí donde me parece importante considerar la categoría "transmodernidad", tal como se ha venido utilizando por el filósofo argentino Enrique Dussel. De entrada digamos que 
la noción se mueve en dirección contraria a lo que muchos grupos de intelectuales y activistas entienden hoy en día por "descolonización". Operando con la curiosa idea de que la modernidad en su conjunto tiene una "lógica profunda" que es el colonialismo, es decir que todo despliegue modernizador es de suyo colonialista, tales grupos se precipitan directo en una actitud radicalmente anti-moderna. Según ellos, descolonizarse significa escapar de la modernidad (identificada con el genocidio de los pueblos, el "epistemicidio" y la destrucción cultural), replegarse en las "epistemologías" sobrevivientes propias de aquellos pueblos que no fueron coaptados enteramente por la modernidad (comunidades indígenas y negras para el caso de las Américas), pues allí se encuentran las semillas de "otro mundo" muy distinto al occidental. ${ }^{9}$ Vincularse orgánicamente con esas "epistemes-otras" es tenido por tales grupos como el acto político emancipador por excelencia. ${ }^{10}$ No obstante, la política que ofrece Dussel tiene en realidad muy poco que ver con esta visión esencialista. ${ }^{11}$ El filósofo argentino no es antimoderno sino transmoderno. ¿Qué significa esto?

Al igual que los otros miembros del grupo modernidad/ colonialidad (Quijano, Grosfoguel, yo mismo), Dussel parte de la tesis de que la modernidad es un fenómeno histórico que tiene un momento "intrauterino" (por así decirlo) con la constitución de la burguesía hacia finales de la edad media europea, pero que adquiere su perfil definitivo gracias a la conquista de América y la creación del mercado mundial con la expansión colonial de las potencias europeas (lo que teóricos marxistas como Immanuel Wallerstein han llamado el "sistema-mundo moderno"). Este sistema mundial coloca 
por primera vez juntas, pero en relación asimétrica, a una gran cantidad de "culturas" que antes habían vivido separadas unas de otras, estableciendo sobre ellas la hegemonía de una concepción primero cristiana y señorial (siglos XVI-XVII), luego racionalista y capitalista ( siglos XVIII-XX) de entender la vida, el conocimiento, la naturaleza y las relaciones sociales. Dussel se refiere específicamente a culturas milenarias como las provenientes de India, China, el mundo árabe y el mundo indígena precolombino. Nótese que la colonización en Dussel no se reduce al "genocidio" y/o la "occidentalización" completa de pueblos y culturas (que sin duda ocurrió en más o menos casos), sino que es, ante todo, el establecimiento de una hegemonía cultural. Esto quiere decir que las culturas de esos pueblos no fueron destruidas (su propio peso histórico milenario lo impedía ${ }^{12}$ ), sino que amplios pliegues de su "sentido común", de su "mundo de la vida" (Lebenswelt), fueron transformados con la introducción del cristianismo, la ciencia moderna, la modernización político-cultural y, sobre todo, el capitalismo. Pero esto significa también que tales pliegues han permanecido en una "exterioridad relativa" con respecto al significado que todos estos procesos adquirieron en Europa. Aquí se muestra el alcance del concepto gramsciano de "hegemonía" utilizado por Dussel. La colonización conlleva el establecimiento de un "consenso" tácito entre los valores occidentales traídos con la colonización europea y los valores propios de las culturas colonizadas, provenientes de su mundo ancestral premoderno. Pero Dussel tiene claro que esos valores ancestrales no han permanecido inalterados con el advenimiento de la modernidad (a la que fueron incorporados por el colonialismo), sino que se han transformado junto con 
ella. No hay ningún tipo de esencialismo cultural en Dussel, similar al que se evidencia en las posiciones "abyayalistas" que mencionamos anteriormente. La exterioridad de las culturas colonizadas es solamente relativa y no absoluta frente a los procesos de modernización. La modernidad es un fenómeno irreversible del cual ninguna cultura en el planeta tierra puede ni podrá sustraerse por entero, tal como lo entrevió Marx.

¿Qué significa entonces la "transmodernidad"? Esta noción apunta hacia el modo en que ese proceso mundial de modernización económica, política y cultural puede ser "asimilado" dialécticamente desde las diferentes culturas subalternizadas por la expansión colonial europea. Significa atravesar la modernidad pero desde "otro lugar", precisamente desde aquellos que fueron "negados" por la modernización hegemónica euro-norteamericana (posicionada como "centro" de la modernidad). En términos de Marx, la transmodernidad sería entonces la "negación de la negación", es decir la asimilación creativa y emancipadora de la modernidad realizada desde historias locales. Se trata de una modernidad vivida desde la exterioridad relativa que niega su forma occidentalista y eurocentrada. Una modernidad, en últimas, descolonizada. Pero tal descolonización no remite, como decimos, a un proyecto antimoderno, sino a un proyecto crítico y emancipatorio frente a las instituciones desarrolladas por la modernidad misma. ${ }^{13}$ Desde esta perspectiva, Dussel entiende la transmodernidad como un proyecto político, económico, social y cultural que marcará una nueva fase de la historia mundial. Un proyecto que, según él, será impulsado por "intelectuales orgánicos" situados en medio (Borderthinking) de su propia cultura subalternizada y 
la modernidad eurocentrada. Son precisamente intelectuales poscoloniales, aquellos que viven "entre dos mundos", quienes pueden establecer las mediaciones culturales necesarias entre la modernidad occidental y los valores de las culturas negadas por ésta durante la expansión colonial, propiciando de este modo la "negación de la negación". Nótese entonces: la transmodernidad no es una operación de "retorno" a los valores de las culturas "nativas" antes de la colonización, sino una "problematización" (como diría Foucault) que tiene dos caras: de un lado, la modernidad eurocentrada es reinterpretada desde las historias locales negadas por la colonización; pero del otro lado, y al mismo tiempo, la propia cultura subalterna, modificada ya indefectiblemente por los procesos de modernización, debe ser reinterpretada críticamente. No hay entonces en Dussel ningún amago de subalternismo, posición que, por desgracia, se ha expandido como un virus en no pocos sectores intelectuales de América Latina, sobre la base de una interpretación políticamente equivocada del "giro decolonial".

Comparto muchos de los análisis que hace Dussel a este respecto y a diferencia de los subalternistas, entiendo la descolonización en el sentido "transmoderno" que él señala. Sin embargo, quisiera realizar algunas observaciones críticas antes de finalizar este trabajo. La primera tiene que ver con su noción de "núcleo ético-mítico", categoría tomada de Paul Ricoeur, que le sirve a Dussel para pensar aquello que define no sólo esta o aquella cultura en particular, sino la cultura en general. Su tesis parece ser que la religión forma parte del "núcleo ético-mítico" presente en todas las culturas. Y sobre la base de esta ontología de la cultura es que Dussel coloca el 
proyecto transmoderno. En el fondo late la creencia de que esos "intelectuales orgánicos" de las culturas subalternas se hallan vinculados de algún modo a las "grandes religiones" de la humanidad: el Budismo, el Hinduismo, el Islam, el Cristianismo. El diálogo transmoderno sería entonces un diálogo entre intelectuales críticos provenientes de o vinculados con las grandes tradiciones religiosas. De ahí su énfasis en la necesidad del diálogo entre los teólogos y los filósofos, como lo deja ver en el apéndice de su último libro Filosofías del Sur.

Quisiera articular una breve reflexión a este respecto. Hay por lo menos cuatro instituciones fundamentales nacidas de la modernidad que necesitamos reinscribir hoy en un escenario transmoderno: la ciencia, el Estado de derecho, la democracia y la crítica. Creo, junto con Dussel, que es posible una transmodernización de estas instituciones y es en este sentido preciso que entiendo el "giro decolonial". La primera de ellas es la ciencia. No podremos garantizar la vida de las poblaciones (como dice Dussel) sin el concurso de la ciencia moderna, enriquecida desde luego con aportes provenientes de las medicinas no occidentales (el llamado «diálogo de saberes»). Rechazar de plano la medicina moderna (por considerarla «imperialista» o «atea») sería un acto de oscurantismo similar al derribamiento de las estatuas de Buda por parte de los Talibanes. La segunda institución (imprescindible por ahora) es el Estado de derecho, que querámoslo o no, continúa siendo el marco básico de la política, aún a pesar de las pretensiones levantadas en los últimos años por los movimientos antiglobalización y otros grupos autogestionarios. En Bolivia, por ejemplo, el Estado de 
derecho no desaparece, sino que integra y reconoce diferentes formas de autoridad y gobierno comunitario, generando así un constitucionalismo de nuevo tipo, como bien lo muestra Boaventura de Sousa Santos. La tercera institución es la democracia, entendida como un imaginario político en el que la igualdad y la libertad son valores universalizables, susceptibles de ser extendidos hacia toda la comunidad. Estos valores no tienen por qué reñir con formas ya existentes de igualitarismo y participación ancladas en diferentes culturas (como la de los caracoles zapatistas a la que hace referencia Dussel), pero debemos entender que la democracia supone el rechazo de todas las jerarquías de poder, así estas formen parte de las «tradiciones culturales» de una comunidad. Finalmente, la cuarta institución que considero básica para una situación transmoderna es la crítica. Con ello me refiero al ejercicio de la problematización, la desnaturalización de lo dado, el cuestionamiento del «sentido común» a través del arte, el debate de ideas, la filosofía, etc. Pero aún en una hipotética situación transmoderna, la reinscripción no eurocéntrica de estas instituciones conllevará, de todos modos, el desafio de asumir la incompletud ontológica que ellas arrastran consigo. Dicho de otro modo: la transmodernidad no puede significar remitir la ciencia, el Estado de derecho, la democracia y la crítica racional a las certezas incuestionadas de un fundamento último, con el argumento de que tales certezas forman parte de la «identidad cultural» de otros pueblos y de que es necesario «inculturar» ahí tales instituciones. Digo esto porque me parece que la categoría dusseliana de «transmodernidad» es heredera del gran debate que se dio en América Latina, sobre todo en círculos de la Iglesia Católica hacia la década de 1970, 
en torno a la necesidad de «inculturar» el evangelio. A raíz del Concilio Vaticano II, los teólogos reflexionaban sobre el modo en que la liturgia católica (largamente desarrollada en Europa) podría vivirse de una forma no eurocéntrica en contextos culturales como el asiático, el africano y el latinoamericano. Esta discusión, que puede ser válida para entender el problema de la interculturalidad religiosa (en el que en todo caso no se cuestiona el tema del fundamento último), me parece algo limitada para entender el modo en que algunas instituciones modernas (cuyo funcionamiento depende de la ausencia de fundamento último) pueden ser experimentadas en contextos culturales no occidentalizados. Por eso afirmo que no debemos entender la transmodernidad como una simple «inculturación» de la modernidad en contextos culturales no europeos.

Corren días difíciles para la humanidad en su conjunto. La extrema derecha parece estar logrando la hegemonía cultural y política en importantes naciones del primer mundo y también en América Latina. Es muy importante comprender que la mejor estrategia para combatir esta tendencia no es el repliegue en las acciones comunitarias, sino la lucha por democratizar los valores anclados en el sentido común de las sociedades y por recuperar la soberanía de las instituciones públicas. No significa esto que la reconstitución de los tejidos comunitarios no sea importante para avanzar en esta lucha. Lo es, y mucho. Pero sería un error dar por perdida la lucha por la hegemonía política de las instituciones sociales (incluyendo desde luego el Estado) en nombre de una "descolonización" que apunta hacia el subalternismo y el autonomismo. Debemos entender que no hay soluciones exclusivamente comunitarias 
para los problemas de sociedades complejas como las nuestras y que la construcción hegemónica de una voluntad común es lo único que puede ofrecernos esperanzas en medio del desierto.

\section{NOTAS}

${ }^{1}$ Profesor de la Pontificia Universidad Javeriana (Bogotá). Doctor en Filosofía en la en la Johann Wolfgang Goethe-Universität de Frankfurt. Correo electrónico: scastro@javeriana.edu.co.

${ }^{2}$ Todos estos argumentos se encuentran desarrollados con amplitud en mi libro Revoluciones sin sujeto. Slavoj Žižek y la crítica del historicismo posmoderno. Madrid / México: Akal 2015

${ }^{3}$ Ernesto Laclau. «Universalismo, particularismo y la cuestión de la identidad», en Emancipación y diferencia, Buenos Aires, Ariel, 1996, p. 54-55

${ }^{4} \mathrm{Al}$ respecto dice Laclau: «En lugar de invertir una relación particular de opresión/cierre en lo que tiene la particularidad concreta, invertir lo que hay en ella de universalidad - la forma de opresión y cierre como tal. La referencia al otro se mantiene también aquí, pero como la inversión tiene lugar al nivel de la referencia universal y no de los contenidos concretos del sistema opresivo, las identidades tanto de los opresores como de los oprimidos son radicalmente modificadas» Ibidem, p. 62

${ }^{5}$ «Universalismo, particularismo y la cuestión de la identidad», en Emancipación $y$ diferencia, cit., p. 47

${ }^{6}$ Ibidem, p. 48

${ }^{7}$ Ibidem, p. 50

${ }^{8}$ Me refiero con ello a la invocación de «Abya Yala» (nombre dado por algunos grupos indígenas a la América prehispánica) como lugar de enunciación de ciertas reivindicaciones políticas (indigenistas, pero también feministas y ecologistas). El problema de este gesto es su tendencia a invocar una exterioridad frente a la modernidad en su conjunto, negando con ello las 
pretensiones de universalidad de la política moderna (y proponiendo un abandono de las tradiciones críticas de la izquierda), por considerarlas una forma de «colonialismo»

${ }^{9}$ Hay que decir, sin embargo, que la obra temprana de Dussel (en los años setenta) favorecía esta actitud anti-moderna, pues presentaba a la modernidad como una "totalidad opresora" en su conjunto. Actitud que será posteriormente moderada por el propio Dussel en la medida en que se deja interpelar por los textos de Marx

${ }^{10}$ Para un análisis crítico de estas posiciones, véase: Castro-Gómez, 2015: 270288

${ }^{11}$ He acuñado la categoría "abyayalismo" en mi libro Revoluciones sin sujeto para referirme a las posiciones que propugnan por un "rescate" de los valores de las culturas nativas previas a la colonización, como si tales valores hubieran permanecido en una exterioridad absoluta frente a las relaciones de poder que los subalternizaron. El abyayalismo es entonces la ilusión de que es posible sustraerse a las relaciones dominantes que definen la posición de las distintas culturas en un sistema jerárquico de clasificación de las poblaciones (eso que Quijano denomina la "colonialidad del poder")

${ }^{12}$ Dussel se refiera a esto con la ambigua categoría ricoeuriana de "núcleo ético-mítico". Véase: Dussel, 2015: 282

${ }^{13}$ Aunque seguramente Dussel preferiría hablar de un diálogo "analéctico" 


\section{REFERENCIAS}

CASTRO-GÓMEZ, Santiago. Revoluciones sin sujeto: Slavoj Žižek y la crítica del historicismo posmoderno. Madrid / México: Akal, 2015.

DUSSEL, Enrique. Filosofias del Sur: descolonización y transmodernidad. Madrid / México: Akal, 2015.

LACLAU, Ernesto. Emancipación y diferencia, Buenos Aires, Ariel, 1996.

ŽIŽEK, Slavoj. El espinoso sujeto: el centro ausente de la ontología política. Buenos Aires/Barcelona/México: Paidós, 2001. 